\title{
Phylogenetic classifications are informative, stable, and pragmatic: the case for monophyletic taxa
}

\author{
P. S. Ward ${ }^{1}$ (1) S. G. Brady ${ }^{2}$ B. L. Fisher ${ }^{3}$ T. R. Schultz ${ }^{1}$
}

Received: 18 August 2016/Revised: 5 September 2016/ Accepted: 7 September 2016/Published online: 19 September 2016 (C) The Author(s) 2016. This article is published with open access at Springerlink.com

In a recent commentary in this journal Seifert et al. (2016) propose returning to a school of classification largely abandoned by systematists, in which both monophyletic and paraphyletic groups are formally recognized. This approach, dubbed "evolutionary classification", has proved to be unattractive and impractical because the basis for taxon recognition is a confounding mix of phylogenetic relatedness and some measure of "degree of divergence". Most systematists and evolutionary biologists now advocate classifications that are strictly phylogenetic, in which all named taxa above the species level are monophyletic (Wiley and Lieberman 2011; Vences et al. 2013; Judd et al. 2016). Hence, in contemporary biology textbooks birds are acknowledged to be part of the reptile clade; non-monophyletic groups such as "Pisces" and "Articulata" have been abandoned; and a primary division of flowering plants into "dicots" and monocots is recognized as untenable (Westheide and Rieger 2013, 2015; Freeman et al. 2014; Sadava et al. 2014; Judd et al. 2016). In entomology, paraphyletic groups such as "Homoptera", "Heterocera", and "Apterygota" are no longer part of insect classification (Gullan and Cranston 2014; Beutel et al. 2014). Others, such as Blattodea, have been redefined to encompass all their descendant taxa, and hence avoid paraphyly—in this case

P. S. Ward

psward@ucdavis.edu

1 Department of Entomology and Nematology, University of California, Davis, CA, USA

2 Department of Entomology, Smithsonian Institution, Washington, DC, USA

3 Department of Entomology, California Academy of Sciences, San Francisco, CA, USA by including termites in the cockroach order (Inward et al. 2007). Of course, vernacular terms exist for some paraphyletic assemblages (moths, algae, fish, invertebrates, etc.), but most of them are no longer treated as formal groups in a classification.

One could argue that scientific controversies should not be decided by majority rule alone, but there are sound reasons why biological systematists overwhelmingly favor a phylogenetic classification. Such a scheme is simply more informative, accurate, and predictive. Birds really are a kind of modified reptile; to place them in a different group, separate from reptiles, obscures this important fact. Similarly, inclusion of termites in the order Blattodea emphasizes that they are indeed "social cockroaches" and this leads to a more insightful understanding of their biology and evolution (Bell et al. 2007). Excluding termites from Blattodea and putting them in their own order, Isoptera, would be positively misleading.

A phylogenetic classification is also, ultimately, more stable: as we refine our understanding of the tree of life, and achieve ever more confident estimates of phylogenetic relationships, systematists are more likely to converge upon a consensus. In a phylogenetic classification not all nodes in the tree of life need to be named, but any group that is named must meet the criterion of monophyly, and this limits the number of available options (Schmidt-Lebuhn 2012). By contrast, allowing paraphyletic groups opens up a can of worms. How distinct does a divergent ingroup have to be to justify excising it from its containing group and thereby render the latter paraphyletic? Given that rates of evolution are highly variable, and also vary among different classes of characters, there would be no end of argument-never resolved satisfactorily_about whether a given group is "sufficiently distinct" to be removed from its containing clade. 
Consider the examples to which Seifert et al. (2016) objected. In our recent reclassification of the ant subfamily Myrmicinae (Ward et al. 2015), we placed lineages of socially parasitic ants into the genera in which they are embedded phylogenetically. Although these parasites had been placed in their own genera on the basis of their divergent phenotypes, our molecular phylogenetic results demonstrated that they are nested within more inclusive genera such as Tetramorium and Temnothorax, which each contain hundreds of species. Ongoing molecular studies show that the social parasites are situated shallowly within their respective host genera (F. Hita Garcia, pers. comm.; M. Prebus, pers. comm.), precluding a simple splitting into several monophyletic subgroups.

Moreover, contrary to the claim by Seifert et al. (2016) that the social parasites have diverged markedly while other congeners have remained more or less phenotypically static, there is a broad range of variability among the other species. For example, Temnothorax ants have undergone an impressive radiation in the Caribbean, producing species that are, at least superficially, far more divergent morphologically from typical Holarctic species of Temnothorax than the social parasites (Fig. 1). But there are varying degrees of extremeness in these Antillean Temnothorax (Fontenla 2000). Where along this range of variation should a break be made? Then there is the erstwhile subgenus $D i$ chothorax, also well embedded in Temnothorax, with unusual mesosomal morphology. Should it be removed too? What about the pale nocturnal Temnothorax that have diversified in the deserts of Baja California? Or the Mesoamerican radiation of the Temnothorax salvini group? Depending on the whim and subjective perceptions of different "evolutionary systematists", various parts of Temnothorax could be amputated, leaving behind an illdefined assortment of species, scattered across the phylogeny.

No matter how such an operation is performed, it would always result in a loss of information content for
Fig. 1 Morphological diversity in workers of the ant genus Temnothorax. a $T$. ravouxi (CASENT0173641), a social parasite formerly known as Myrmoxenus ravouxi, $\mathbf{b} T$. unifasciatus

(CASENT0173188), the most commonly used host species of T. ravouxi, $\mathbf{c} T$. pergandei (CASENT0104016), formerly in subgenus Dichothorax, $\mathbf{d} T$. salvini (CASENT0010847), part of a Mesoamerican radiation of the genus, e $T$. bca05 (CASENT0118165), a member of a species complex occurring in the deserts of Baja California, f $T$. poeyi (CASENT0106241), an extreme representative of the Caribbean radiation of Temnothorax. Images from AntWeb (http://www.antweb. org)
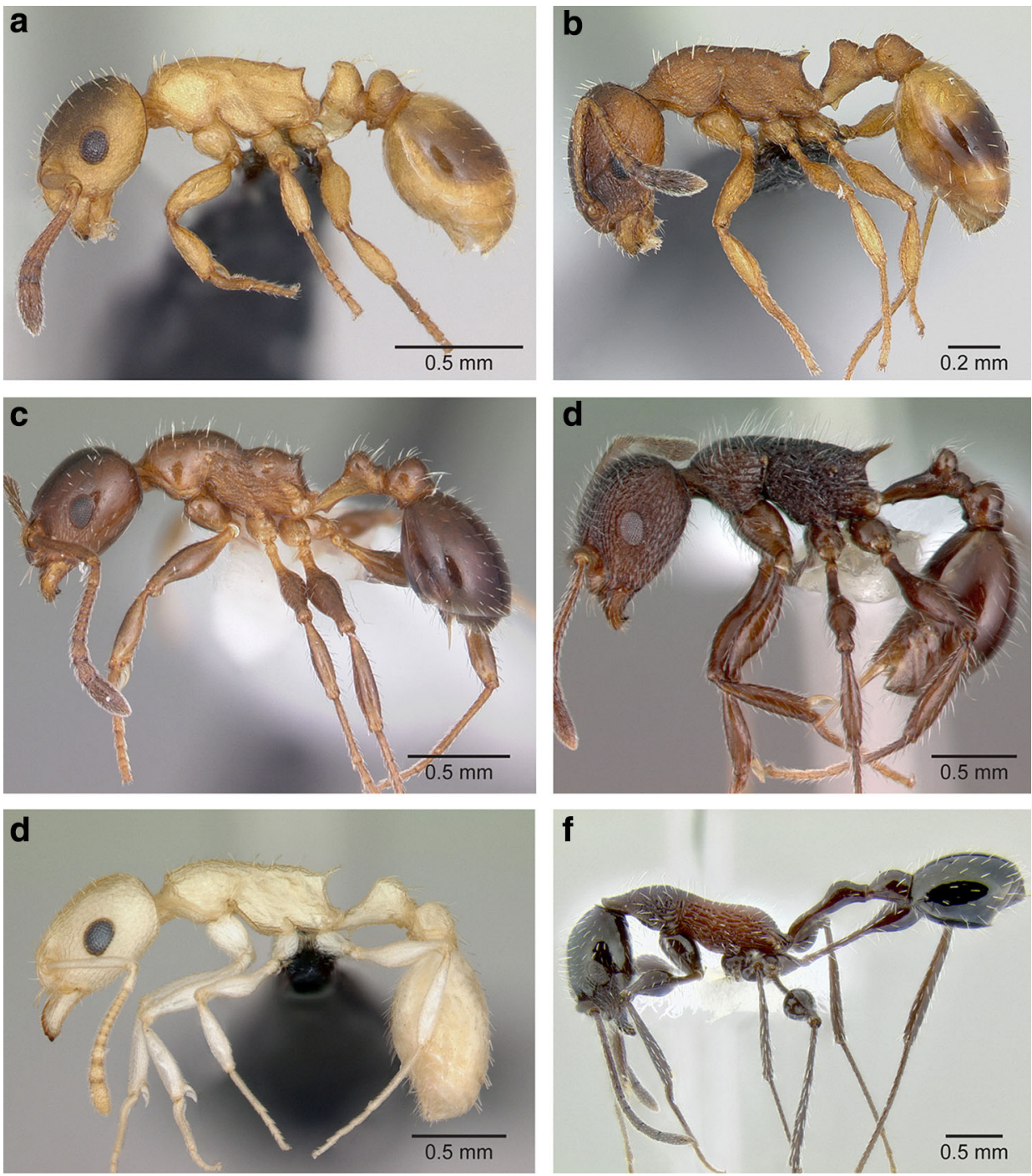
Temnothorax. Under a phylogenetic classification, Temnothorax contains all members that share a most recent common ancestor. Under any paraphyletic formulation, this does not hold true. The increased efficiency of information retrieval that a phylogenetic system produces has been recognized in the literature for some time (Cracraft 1974; Farris 1979; see also Schmidt-Lebuhn 2013).

The argument that communication is hindered by adoption of a phylogenetic classification also does not stand up to scrutiny. The former parasite genera can be referred to using informal species-group names. For a period of time one could append the old genus name, e.g., "ravouxi-group (former Myrmoxenus)", until usage of the species-group name takes over. There are numerous examples among ants of other satellite genera that were previously synonymized under their containing clades: Doronomyrmex under Leptothorax; Sifolinia under Myrmica; Anergatides, Bruchomyrma, Sympheidole and others under Pheidole; various former genera under Strumigenys, etc. No-one is any longer decrying the loss of these genus names; the species names (or informal species-group names) are still available and permit ready communication about the taxa concerned.

It is ironic that Seifert et al. (2016) exhort the reader to consider the experience of plant systematists. In fact, there have been major advances in the systematics of flowering plants, as botanists have developed a revised phylogenetic classification that incorporates the findings from molecular studies (Stevens 2016). The Angiosperm Phylogeny Group (APG) project is an excellent example of how the Linnaean system can be modified to accommodate new phylogenetic knowledge and to reflect relatedness (Angiosperm Phylogeny Group 2016). Seifert et al. (2016) fail to mention the APG initiative; instead they cite two botanists whose views (e.g., Stuessy \& Hörandl 2014) are at variance with those of most plant systematists (cf. Kadereit et al. 2016).

Of course there can be challenges to the establishment of a ranked phylogenetic classification-in principle, for example, when dealing with putatively ancestral taxa (Schmidt-Lebuhn 2012), and in practice when faced with variable rates of morphological evolution among extant species (Ward 2011), and differing opinions about taxon circumscription and diagnosability (Christenhusz et al. 2015). The APG classification has undergone multiple iterations and is still the subject of ongoing discussionmotivated in part by new phylogenetic information, or by lingering uncertainties about relationships-but thanks to the unifying principle of phylogenetic relatedness a measure of consensus has been achieved that is difficult to imagine under the alternative of an "evolutionary classification".

We are at an exciting time in the study of ants and other social insects where molecular data-increasingly at the genome scale (e.g., Blaimer et al. 2015)—is yielding unprecedented insight into their evolutionary history. Indeed, the whole-genome scans of socially parasitic ants and their hosts advocated by Seifert et al. (2016) have already commenced (e.g., in Pogonomyrmex and Vollenhovia; Smith et al. 2015), guided by the same phylogenetic context that also supports the classification of these social parasites in the same genera as their hosts. The advent of robust molecular phylogenies presents an opportunity to revise the taxonomy of social insects in line with new findings, and thereby establish a more stable and informative classification. The call by Seifert et al. (2016) to return to an outdated classification scheme would reverse this progress, and it should not be heeded.

Acknowledgments We thank Rolf Beutel, Francisco Hita Garcia, Matthew Prebus, Susanne Renner and two anonymous reviewers for helpful comments and discussion.

Open Access This article is distributed under the terms of the Creative Commons Attribution 4.0 International License (http:// creativecommons.org/licenses/by/4.0/), which permits unrestricted use, distribution, and reproduction in any medium, provided you give appropriate credit to the original author(s) and the source, provide a link to the Creative Commons license, and indicate if changes were made.

\section{References}

Angiosperm Phylogeny Group (2016) An update of the Angiosperm Phylogeny Group classification for the orders and families of flowering plants: APG IV. Bot J Linn Soc 181:1-20. doi:10.1111/ boj. 12385

Bell WJ, Roth LM, Nalepa CA (2007) Cockroaches: ecology, behavior, and natural history. John Hopkins University Press, Baltimore

Beutel RG, Friedrich F, Ge S-Q, Yang X-K (2014) Insect morphology and phylogeny: a textbook for students of entomology. De Gruyter, Berlin

Blaimer BB, Brady SG, Schultz TR, Lloyd MW, Fisher BL, Ward PS (2015) Phylogenomic methods outperform traditional multi-locus approaches in resolving deep evolutionary history: a case study of formicine ants. BMC Evol Biol 15:257. doi:10.1186/s12862-015$0552-5$

Christenhusz MJM, Vorontsova MS, Fay MF, Chase MW (2015) Results from an online survey of family delimitation in angiosperms and ferns: recommendations to the Angiosperm Phylogeny Group for thorny problems in plant classification. Bot J Linn Soc 178:501-528. doi:10.1111/boj.12285

Cracraft J (1974) Phylogenetic models and classification. Syst Zool 23:71-90. doi:10.1093/sysbio/23.1.71

Farris JS (1979) The information content of the phylogenetic system. Syst Zool 28:483-519. doi:10.2307/sysbio/28.4.483

Fontenla JL (2000) Historical biogeography and character evolution in the phylogenetic taxon "Macromischa" (Hymenoptera: Formicidae: Leptothorax). Trans Am Entomol Soc 126:401-416

Freeman S, Allison L, Black M, Podgorski G, Quillin K, Monroe J, Taylor E (2014) Biological science, 5th edn. Pearson, Boston

Gullan PJ, Cranston PS (2014) The insects: an outline of entomology, 5th edn. Wiley, Chichester 
Inward D, Beccaloni G, Eggleton P (2007) Death of an order: a comprehensive molecular phylogenetic study confirms that termites are eusocial cockroaches. Biol Lett 3:331-335. doi:10. 1098/rsbl.2007.0102

Judd WS, Campbell CS, Kellogg EA, Stevens PF, Donoghue MJ (2016) Plant systematics: a phylogenetic approach, 4th edn. Sinauer, Sunderland

Kadereit JW, Albach DC, Ehrendorfer F, Galbany-Casals M, GarciaJacas N, Gehrke B, Kadereit G, Kilian N, Klein JT, Koch MA, Kropf M, Oberprieler C, Pirie MD, Ritz CM, Röser M, Spalik K, Susanna A, Weigend M, Welk E, Wesche K, Zhang L-B, Dillenberger MS (2016) Which changes are needed to render all genera of the German flora monophyletic? Willdenowia 46:1-39. doi:10.3372/wi.46.46105

Sadava S, Hillis DM, Heller HC, Berenbaum MR (2014) Life, 10th edn. Sinauer, Sunderland

Schmidt-Lebuhn AN (2012) Fallacies and false premises-a critical assessment of the argument for the recognition of paraphyly taxa in botany. Cladistics 28:174-187. doi:10.1111/j.1096-0031.2011. 00367.x

Schmidt-Lebuhn AN (2013) "Evolutionary" classifications do not have any information content-a reply to Stuessy and Horandl. Cladistics 30:229-231. doi:10.1111/cla.12037

Seifert B, Buschinger A, Aldawood A, Antonova V, Bharti H, Borowiec L, Dekoninck W, Dubovikoff D, Espadaler X, Flegr J, Georgiadis C, Heinze J, Neumeyer R, Ødegaard F, Oettler J, Radchenko A, Schultz R, Sharaf M, Trager J, Vesnić A, Wiezik M, Zettel H (2016) Banning paraphylies and executing Linnaean taxonomy is discordant and reduces the evolutionary and semantic information content of biological nomenclature. Insect Soc 63:237-242. doi:10.1007/s00040-016-0467-1
Smith CR, Cahan SH, Kemena C, Brady SG, Yang W, Bornberg-Bauer E, Eriksson T, Gadau J, Helmpkampf M, Gotzek D, Miyakawa MO, Suarez A, Mikheyev A (2015) How do genomes create novel phenotypes? Insights from the loss of the worker caste in ant social parasites. Mol Biol Evol 32:2919-2931. doi:10.1093/ molbev/msv165

Stevens PF (2016) Angiosperm phylogeny website, version 13. http:// www.mobot.org/MOBOT/research/APweb/. Accessed 15 August 2016

Stuessy TF, Hörandl E (2014) Evolutionary systematics and paraphyly: introduction. Ann Mo Bot Gard 100:2-5. doi:10.3417/ 2012083

Vences M, Guayasamin JM, Miralles A, de la Riva I (2013) To name or not to name: criteria to promote economy of change in Linnaean classification schemes. Zootaxa 3636:201-244. doi:10.11646/ zootaxa.3636.2.1

Ward PS (2011) Integrating molecular phylogenetic results into ant taxonomy. Myrmecol News 15:21-29

Ward PS, Brady SG, Fisher BL, Schultz TR (2015) The evolution of myrmicine ants: phylogeny and biogeography of a hyperdiverse ant clade (Hymenoptera: Formicidae). Syst Entomol 40:61-81. doi:10.1111/syen.12090

Westheide W, Rieger G (eds) (2013) Spezielle Zoologie. Teil 1: Einzeller und Wirbellose Tiere, 3rd edn. Springer-Spektrum, Berlin

Westheide W, Rieger G (eds) (2015) Spezielle Zoologie. Teil 2: Wirbel- oder Schädeltiere, 3rd edn. Springer-Spektrum, Berlin

Wiley EO, Lieberman BS (2011) Phylogenetics: theory and practice of phylogenetic systematics, 2nd edn. Wiley-Blackwell, Hoboken 